\title{
Access to Macrocycles with an endo Aryl Ether and an endo Aryl-Aryl Bond, Development and Application
}

\author{
Qian Wang and Jieping Zhu*
}

\begin{abstract}
Macrocyclization methodologies allowing access to macrocycles having an endo aryl ether and an endo aryl-aryl bond, especially those based on an intramolecular $S_{N} A r$ reaction and the Suzuki-Miyaura reaction, are summarized. Total synthesis of complestatin, a bis-macrocyclic natural product, featuring these two technologies are presented.
\end{abstract}

Keywords: Complestatin - Macrocycle $\cdot$ Macrocyclization $\cdot S_{N} A r$ reaction $\cdot$ Suzuki-Miyaura reaction . Vancomycin

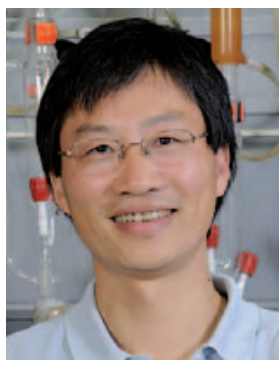

Jieping Zhu received his B.Sc from Hangzhou Normal University and a M.Sc. degree from Lanzhou University (P. R. China) under the guidance of Professor Yulin Li. He got his Ph.D. degree in 1991 from University Paris XI, France under the supervision of Professor H.P. Husson and Pr. J. C. Quirion. After 18 months post-doctoral stay with Professor Sir D. H. R. Barton at Texas A \& M University in USA, he joined Institut de Chimie des Substances Naturelles, CNRS, France in December 1992 as Chargé de Recherche and was promoted to Director of Research in 2000. He moved to Ecole Polytechnique Fédérale de Lausanne, Switzerland in September 2010 as full professor. The development of novel synthetic methods, their application in the synthesis of bioactive natural products, the design of novel multicomponent reactions and more recently, development of catalytic enantioselective transformations are his main research interests. He has published over 200 research papers and co-edited one book.
${ }^{*}$ Correspondence: Prof. J. Zhu Institute of Chemical Sciences and Engineering Ecole Polytechnique Fédérale de Lausanne EPFL-SB-ISIC-LSPN, CH-1015 Lausanne E-mail: jieping.zhu@epfl.ch

\section{Introduction}

Macrocycles, by virtue of their widespread occurrence in nature and their intrinsic three-dimensional structures, play an important role in chemistry, in biology and are medicinally relevant. ${ }^{[1]}$ Indeed various important drugs, such as cyclosporine, macrolides (erythromycin) and the vancomycin family glycopeptides, contain a macrocyclic element. Furthermore, turning linear molecules into macrocyclic structures is an important tool to manipulate the properties of compounds. Indeed, bioactive linear peptides can exist in a myriad of different conformations, very few of which are able to bind to their receptor. ${ }^{[2]}$ Cyclization is a common approach to force peptides to adopt bioactive conformations and to access their important structural and dynamic properties. ${ }^{[3]}$ In addition, cyclopeptides are much more resistant to in vivo enzymatic degradation than their linear counterparts. Apart from pharmaceutical applications, macrocycles have also found wide applications in polymers, ${ }^{[4]}$ in supramolecular chemistry, ${ }^{[5]}$ and in nanomaterials. ${ }^{[6]}$

To address the synthesis of macrocyclic natural products or any designed macrocycles with a specific purpose, ring closure is naturally the key step that will determine the efficacy of the overall synthetic strategy. Not surprisingly, the challenging problem of macrocyclization has attracted attention of synthetic chemists and provided impetus for the development of new synthetic technologies. In connection with our work in the synthesis of vancomycin and related natural products, we developed an intramolecular $\mathrm{S}_{N} \mathrm{Ar}$ reaction ${ }^{[7]}$ and an intramolecular Suzuki-Miyaura reaction ${ }^{[8,9]}$ for the access of macrocycles with an endo aryl ether (reaction 1, Scheme 1) and an endo aryl-aryl bond (reaction 2, Scheme $1)$, respectively. In this article, the development of these two reactions and their recent applications in the total synthesis of complestatin (1) will be briefly discussed.

\section{2. $S_{N} A r$ Reaction-based Cycloetherification}

The glycopeptide antibiotics of the dalbaheptide family, exemplified by vancomycin (2, Fig. 1), are important in the treatment of infections caused by Grampositive organisms, especially those that are $\beta$-lactam resistant. ${ }^{[10]}$ Vancomycin has been used in hospitals since 1958, long before its structural determination. The antibacterial activity of this family of antibiotics arises from specific binding of glycopeptides to bacterial cell wall precursors terminating in the sequence D-AlaD-Ala, inhibiting thus transglycosylation (chain elongation) and transpeptidation (cross-linking). The major advantage of vancomycin therapy is the virtual absence of cross-resistance with other antibiotics for over 35 years. Indeed, it has been a drug of choice and in fact, the drug of last-resort for treatment of serious infections due to methicillin-resistant Staphylococcus aureus and other gram-positive microorganisms. Unfortunately, resistance to vancomycin has been recognized since 1986. Biosynthesis of a D-Ala-D-lactate depsipeptide and its incorporation as the terminal peptidoglycan of resistant bacteria has been proposed as one of the principal mechanisms of resistance. ${ }^{[11]}$

Vancomycin has been considered as one of the molecular summits ${ }^{[12]}$ and extensive efforts have been devoted to its synthesis from 1980s onward. As macrolactamization turned out to be ineffective for the access to 


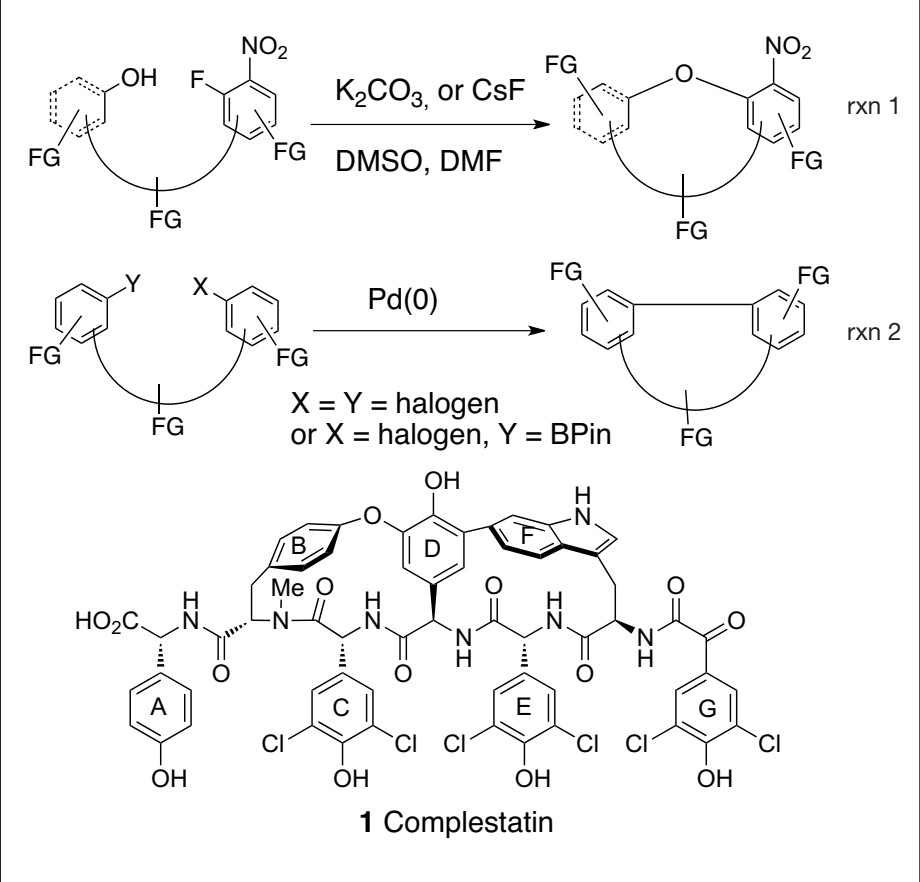

Scheme 1.

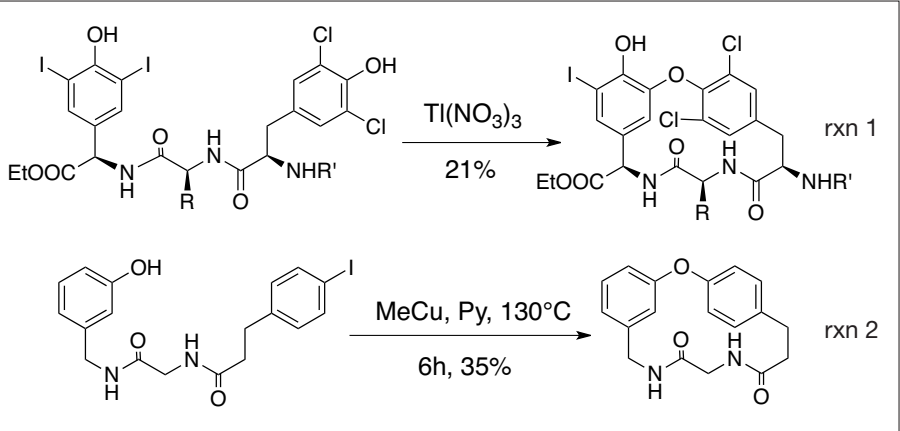

Scheme 2.

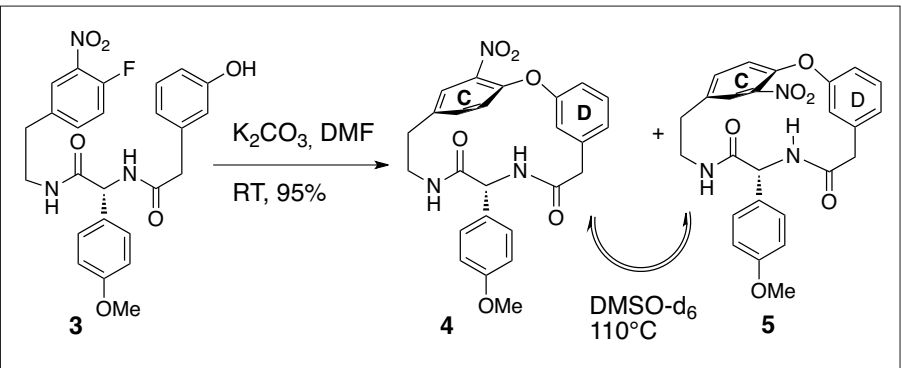

Scheme 3. 16-membered C-O-D and D-O-E rings, ${ }^{[13]}$ an alternative ring closure site was sought and the biaryl ether bond was selected as a strategic bond. Towards this end, Yamamura, Nishiyama and their coworkers developed an elegant thallium trinitrate (TTN) promoted intramolecular phenolic oxidative coupling reaction of tetra-halogenated bisaryl substrates (reaction 1, Scheme 2). ${ }^{[14]}$ The power of this reaction was illustrated in their total synthesis of $\mathrm{K}-13,{ }^{[15]}$ piperazinomycin, ${ }^{[16]}$ deoxybouvardin ${ }^{[17]}$ and vancomycin model.[18] The method, modified by Evans' group, has been applied to their synthesis of advanced bicyclic vancomycin model ${ }^{[19]}$ and orienticin C aglycon. ${ }^{[20]}$ Alternatively, on modifying the classic reaction conditions and choosing judiciously reaction partners, Boger and co-workers disclosed a macrocyclization procedure based upon the intramolecular Ullmann reaction (reaction 2, Scheme 2) and have successfully applied it in the total synthesis of piperazinomycin, ${ }^{[21]}$ bouvardin ${ }^{[22]}$ and simple

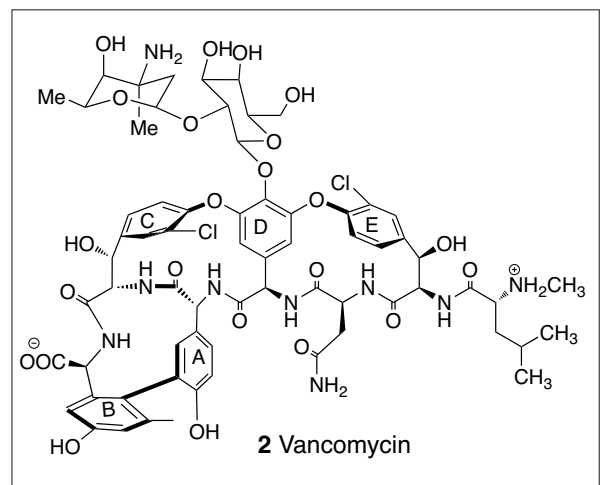

Fig. 1. vancomycin models. ${ }^{[23]}$ However, the presence of the very racemization-prone arylglycins in vancomycin hampered further application of the Ullmann-based strategy which, even under improved conditions, still requires heating in pyridine at $130{ }^{\circ} \mathrm{C}$ in the presence of strong bases.

We have developed a cycloetherification reaction based on an intramolecular nuclophilic aromatic substitution reaction ( $\mathrm{S}_{\mathrm{N}} \mathrm{Ar}$, Scheme 3). ${ }^{[24]}$ Thus, simply stirring a DMF solution of a linear amide 3 in the presence of potassium carbonate at room temperature afforded the 16-membered $m, p$-cyclophane in $94 \%$ yield in the form of two separable atropisomers. Characteristic features of this reaction are as follows: a) very mild conditions (weak base, room temperature), a prerequisite for its future application in the synthesis of vancomycin family glycopeptides that contain very racemization-prone arylglycins; b) simple experimental conditions: no high dilution technique was required and the macrocyclization can be performed typically at 0.01 $\mathrm{M}$ without the interference of competitive oligomerization/polymerization; c) generally high yield and large application scope; d) the presence of the nitro group provided a handle for the introduction of the desired functions like hydrogen, chlorine, and hydroxyl etc. frequently found in natural products; e) the presence of the nitro group ortho to the biaryl ether linkage also provided an opportunity to study the atropdiastereoselectivity of the cyclization. In fact, due to the high ring strain of the 16-membered $m, p$-cyclophane, the rotation around the aryl ether bond was hindered creating therefore a planar chirality if a substituent was introduced ortho to the aryl ether bond, as it is the case for vancomycin.

The reaction worked equally well for the synthesis of cyclophane having an endo aryl-alkyl ether bond (Scheme 4). Thus, cyclization of $\mathbf{6}$ in DMSO in the presence of TBAF and $3 \AA$ molecular sieves at $85^{\circ} \mathrm{C}$ afforded the desired 14-membered ansacyclophane 7 as a single atropisomer in $45 \%$ yield after acylation of the benzylic alcohol. It is interesting to note that the reacting secondary alcohol in compound 6 is highly hindered since it is flanked by a bulky isopropyl and an $N, N$-dibenzylamino group at the adjacent positions. This unfavorable steric effect may account for the moderate cyclization yield.

This cycloetherification reaction is not limited to the linear peptides and biaryls tethered by a hydrocarbon chain underwent efficient cyclization as well (Scheme 5). Thus simply stirring a DMF solution of

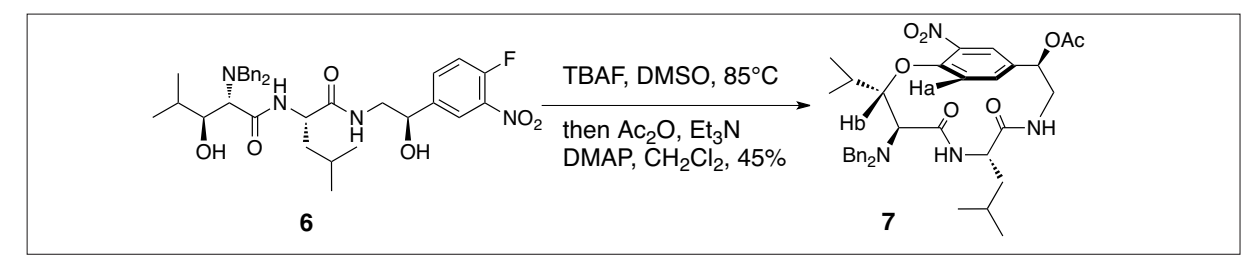

Scheme 4. 


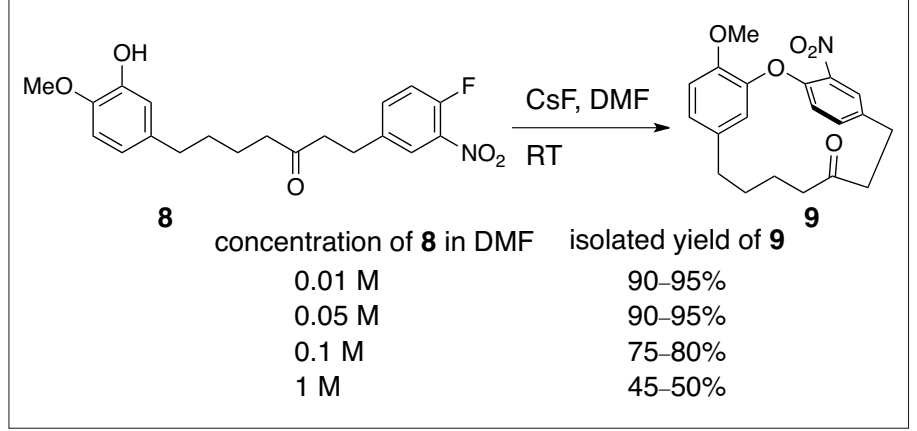

Scheme 5 .

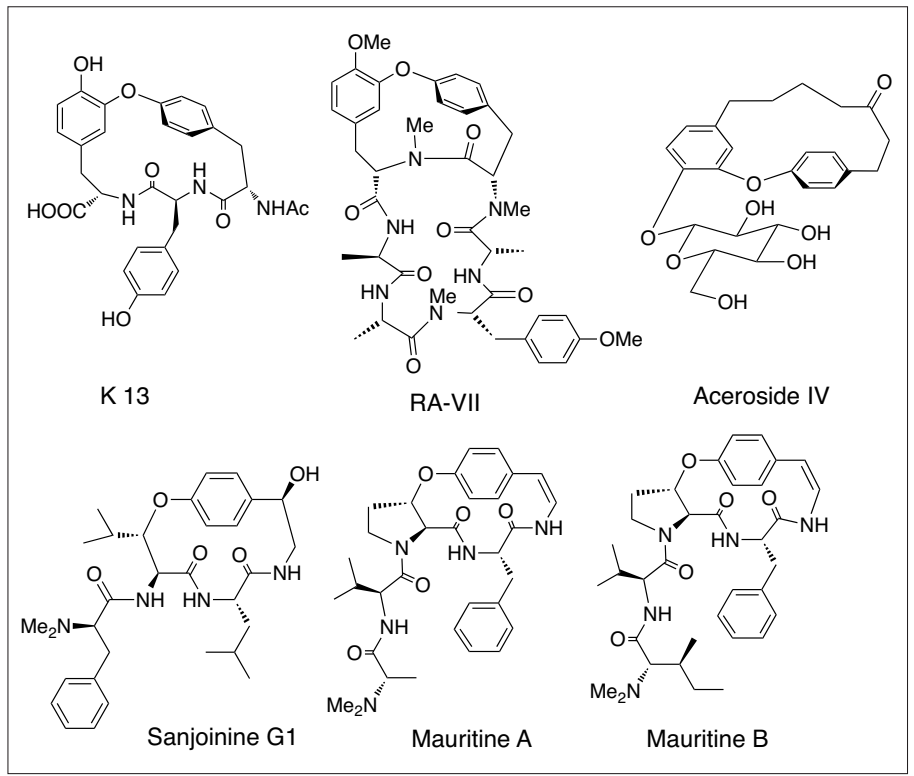

Fig. 2.

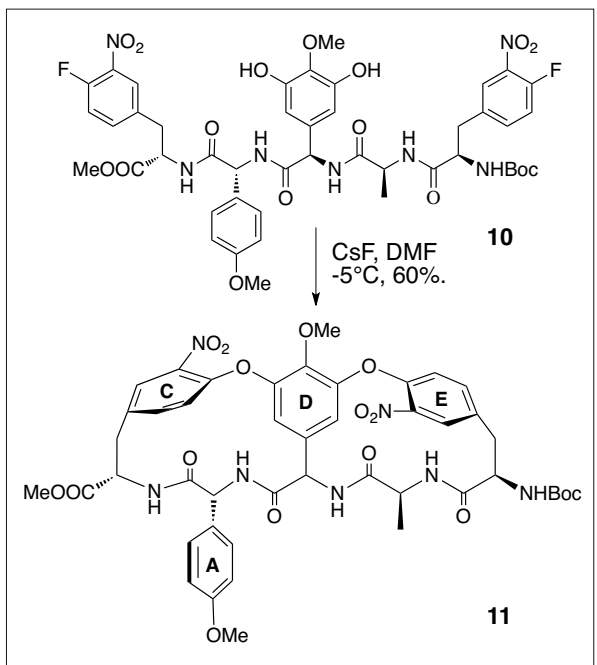

Scheme 6.

8 in the presence of $\mathrm{CsF}(\mathrm{c}=0.01 \mathrm{M})$ provided the 15 -membered $m, p$-cyclophane 9 in over $90 \%$ yield. It is worthy noting that even at $\mathrm{c}=1.0 \mathrm{M}$, the desired macrocyclization of $\mathbf{8}$ still took place as a major reaction pathway to afford $\mathbf{9}$ in about $50 \%$ yield. The propensity of $\mathbf{8}$ for macrocyclization is indeed extraordinary. We assumed that compound $\mathbf{8}$ might adopt a

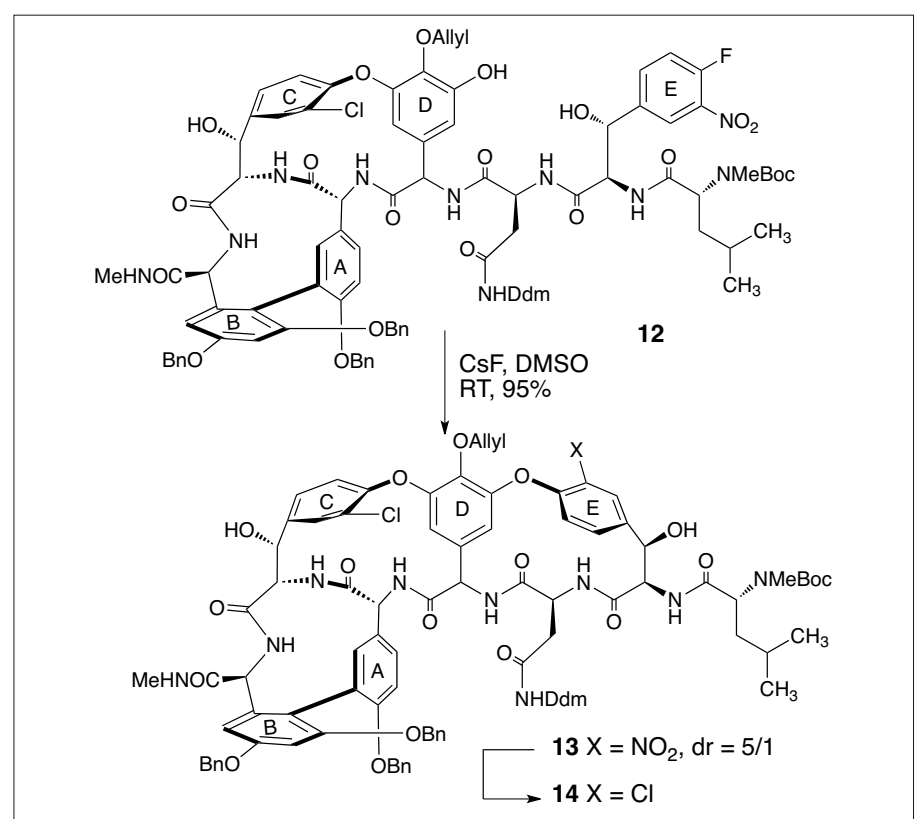

Scheme 7.

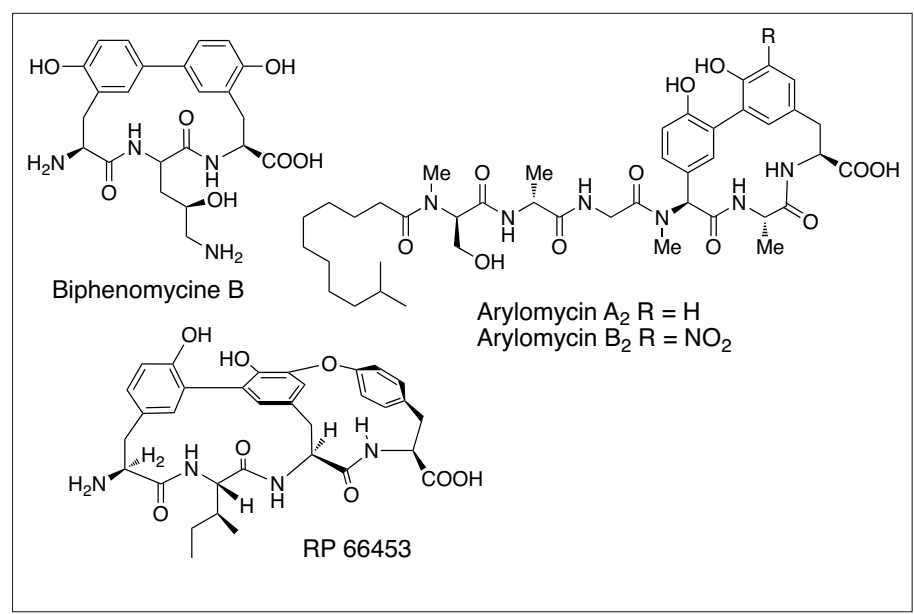

Fig. 3.

bent conformation that is particularly conducive to the macrocyclization. [25]

Using this novel cycloetherification methodology as a key ring-forming step, a number of natural products including $\mathrm{K}-13,{ }^{[26]} \mathrm{RA}-\mathrm{VII},{ }^{[27]}$ aceroside IV,[28] sanjoinine $\mathrm{G} 1,{ }^{[29]}$ mauritines ${ }^{[30]}$ etc. have been synthesized in our laboratory (Fig. 2). Onepot double cyclization of $\mathbf{6}$ illustrated the power of intramolecular $\mathrm{S}_{\mathrm{N}} \mathrm{Ar}$ reaction in the synthesis of macrocycle of vancomycin type. Treatment of a DMF solution of pentapeptide $\mathbf{1 0}$ in the presence of cesium fluoride at $-5{ }^{\circ} \mathrm{C}$ afforded the bis-macrocycle 11 in $60 \%$ yield (Scheme 6). ${ }^{[31]}$ The reaction was highly diastereoselective and afforded $\mathbf{1 1}$ as a single diastereoisomer.

The intramolecular $\mathrm{S}_{\mathrm{N}} \mathrm{Ar}$ reaction has been used as a key reaction in the three known total syntheses of vancomycin aglycon. ${ }^{[32]}$ The last ring-forming step in Evans' synthesis is depicted in Scheme 7. Thus cyclization of $\mathbf{1 2}$ in the presence of CsF afforded tricycle $\mathbf{1 3}$ with desired planar chirality in about $79 \%$ yield together with its atropdiastereomer (15\% yield). Conversion of nitro group to chloride via its diazonium intermediate followed by deprotection afforded then the vancomycin aglycon.

\section{Intramolecular Suzuki-Miyaura Reaction}

Macrocycles having an endo aryl-aryl bond constitute yet another unique family of natural products. Besides vancomycin which contains a 12-membered biaryl-containing macrocycle ( $\mathrm{AB}$ ring), biphenomycin $\mathrm{B}$, arylomycin $\mathrm{A}_{2}, \mathrm{~B}_{2}$ and bicyclic RP 66453 having such structural feature are listed in Fig. 3. Besides macrolactamization, ${ }^{[33]}$ a number of ring closure reactions via formation of aryl-aryl bonds have been developed including nickel(0)promoted intramolecular Ullmann-type reductive coupling of aryl halide, ${ }^{[34]}$ biogenetically relevant intramolecular oxidative coupling of electron-rich arenes, ${ }^{[35]}$ 


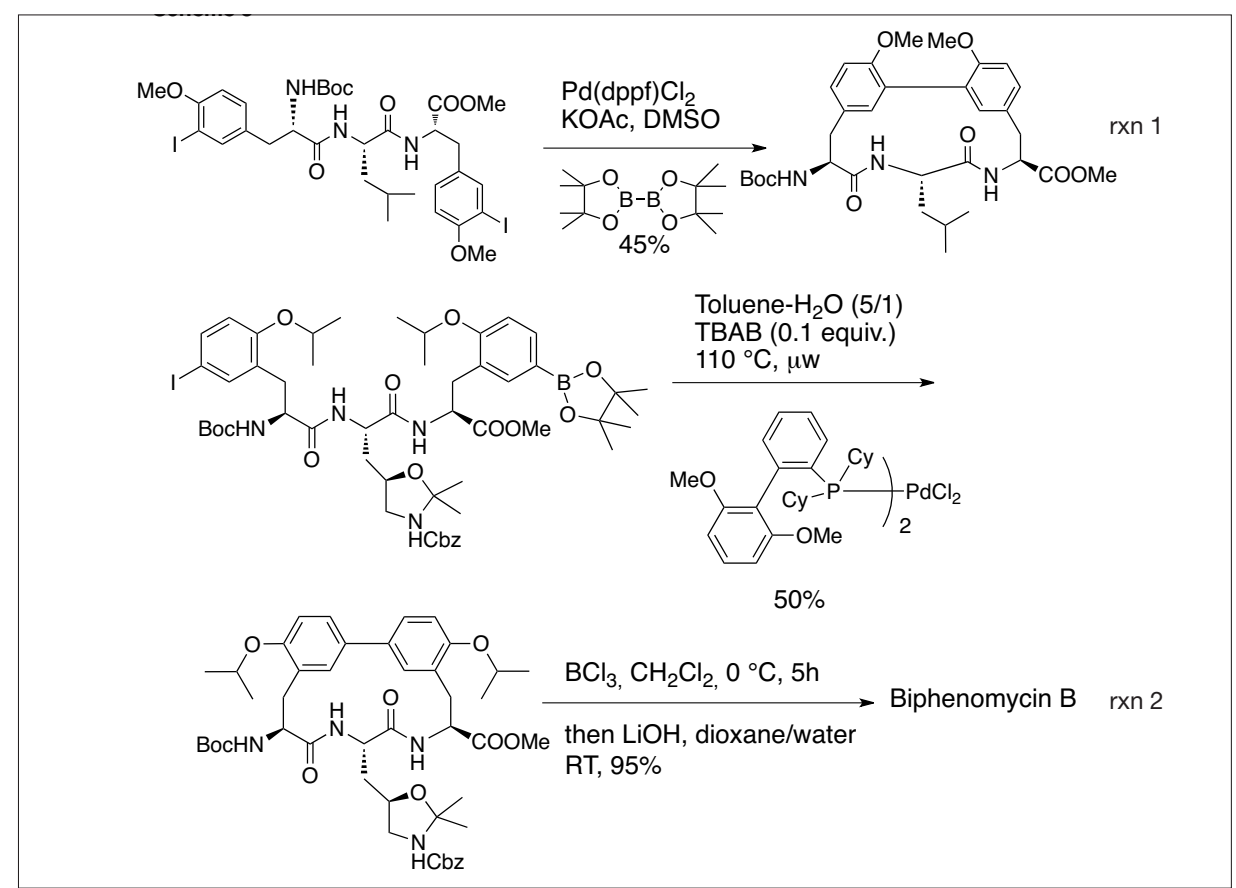

Scheme 8.

and redox-neutral photochemical cyclization. ${ }^{[36]}$

We have been working on this type of macrocycles and have developed two related approaches. One approach involved a novel palladium-catalyzed, diboron ester-mediated cyclization of linear diaryl halides (reaction 1, Scheme 8). The other used an intramolecular Suzuki-Miyaura reaction for the formation of macrocycles (reaction 2, Scheme 8). These reactions have been successfully applied to the total synthesis of biphenomycin $\mathrm{B},{ }^{[37]}$ arylomycin $\mathrm{A}_{2},{ }^{[38]} \mathrm{B}_{2}{ }^{[39]}$ and an atropisomer of RP-66453.[40] The latter synthesis has in addition allowed the determination of the absolute configuration of the natural product including the axial chirality.

\section{Total Synthesis of Complestatin}

Complestatin (1) was first isolated in 1980 from the mycelium of Streptomyces lavendulae as an inhibitor of alternative pathway of complement. ${ }^{[41]}$ Its planar structure was elucidated by Seto in 1989.[42] The absolute configuration of the amino acid constituents of $\mathbf{1}$ was elucidated through detailed NMR, computational as well as degradation studies. ${ }^{[43]}$ Interestingly, although the shape of the rings and central strand in $\mathbf{1}$ resembles strongly that of vancomycin (2), the biological activities of complestatin (1) are completely different from that of vancomycin (2). Indeed, $\mathbf{1}$ is inactive against gram-positive bacteria, but displays potent activities against HIV-1 induced cytopathicity and syncyctium formation in CD-4 lymphocytes and inhibit HIV replication by inhibition of gp 120-CD-4 binding at a low-micromolar level $\left(\mathrm{IC}_{50}=\right.$ 3.3 and $2.0 \mu \mathrm{M}$, respectively). ${ }^{[44]}$ It has also been demonstrated that complestatin blocks both NMDA and AMPA neurotoxicity in a non-competitive and reversible fashion. Therefore, it could also be potentially useful for preventing excitotoxicity under certain pathological conditions. ${ }^{[45]}$

The complex molecular architecture and important biological activities of $\mathbf{1}$ have attracted much attention and have provided chemists with impetus for the development of new synthetic strategies. The group of Snapper and Hoveyda accomplished the first total synthesis of chloropeptin I (15), differing from 1 only at the position of the phenyl-indole ring junc-

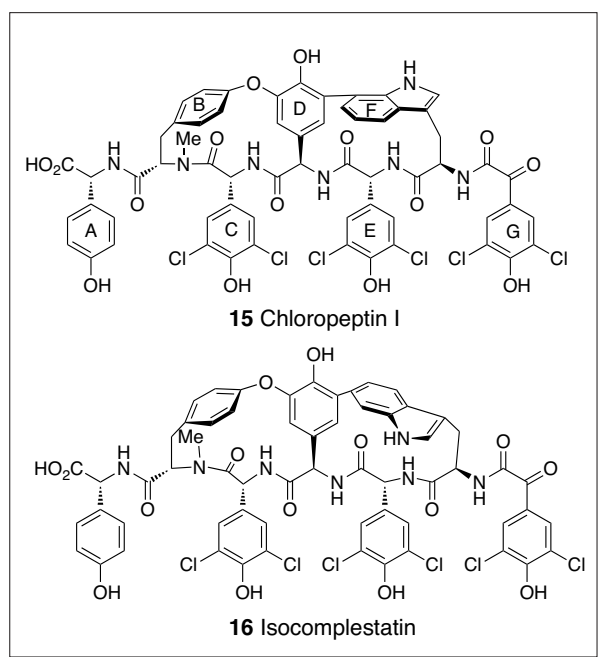

Fig. 4.

tion $^{[46]}$ and an atropisomer of complestatin named isocomplestatin (16, Fig. 4). ${ }^{[47]}$ These total syntheses have also allowed Snapper and Hoveyda to assign the $(a R)$ configuration to the axial chirality of both natural products $\mathbf{1}$ and $\mathbf{1 5}$. More recently Boger and co-workers published the first total synthesis of complestatin. ${ }^{[48]}$

To develop a successful synthesis of complestatin, two key issues need to be addressed, namely: a) avoiding epimerization during and after peptide coupling since complestatin contains four aryl glycins, known to be extremely prone to racemization even under mild basic conditions; ${ }^{[49]}$ b) construction of strained bismacrocycles with defined atropstereochemistry. In addition to the choice of ring closure methodologies, the order of ring formation is expected to influence the overall synthetic efficiency as well as the atropdiastereoselectivity of the synthetic strategy.

Our first strategy that led to the synthesis of isocomplestatin $\mathbf{1 5}$ is shown retro-

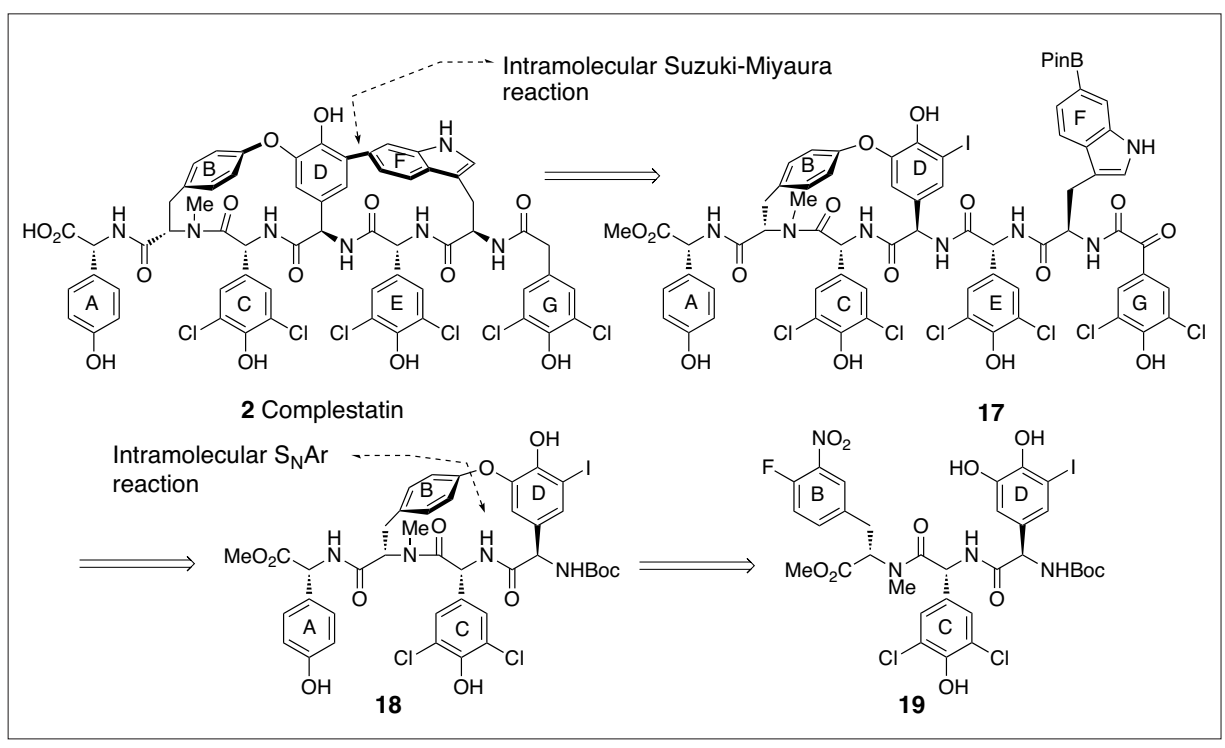




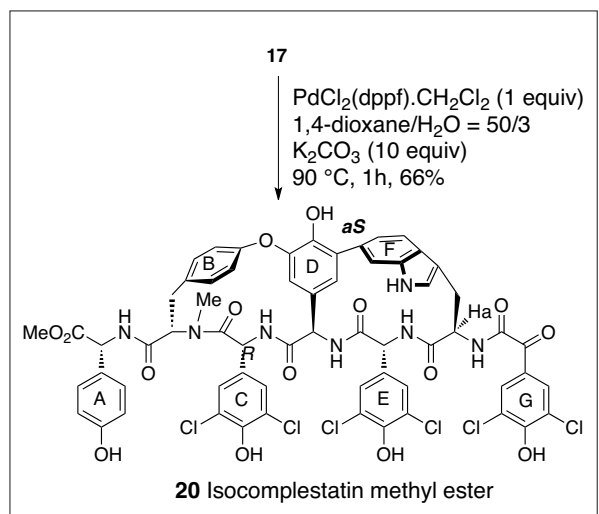

Scheme 10.

synthetically in Scheme 9. ${ }^{[50]}$ In a forward sense, we projected to build firstly the B$\mathrm{O}-\mathrm{D}$ ring by an intramolecular $\mathrm{S}_{\mathrm{N}} \mathrm{Ar}$ reaction, then the D-F ring by intramolecular Suzuki-Miyaura reaction. After significant efforts dedicated to the condition optimization to avoid the racemization of the aryl glycin, we were finally able to access $\mathbf{1 9}$ in an efficient way. Cycloetherification of $19\left(\mathrm{~K}_{2} \mathrm{CO}_{3}, \mathrm{DMSO}, \mathrm{c}=0.003 \mathrm{M}, \mathrm{RT}\right.$, $36 \mathrm{~h}$ ) worked nicely to afford the desired 16-membered $m, p$-cyclophane $\mathbf{1 8}$ in $\mathbf{7 2 \%}$ yield as a single atropisomer. Although of no consequence, the planar chirality of $\mathbf{1 8}$ was determined to be $p S$ on the basis of NOE studies.

Following a sequence of functional group manipulation and peptide coupling, cyclophane 18 was converted to hexapeptide 17. Intramolecular Suzuki-Miyaura reaction of $\mathbf{1 7}$ under conditions optimized for this substrate afforded isocomplestatin methyl ester 20 in $66 \%$ yield (Scheme 10). Although the cyclization was highly atropdiastereoselective, it furnished unfortunately exclusively the wrong atropisomer. Attempts to convert $\mathbf{2 0}$ to the complestatin methyl ester via thermal atropisomerization failed. Only partial decomposition was observed at temperatures higher than $140{ }^{\circ} \mathrm{C}$.

As the observed atropselectivity during the Suzuki-Miyaura reaction is a substrate-dependant process, we envisaged modifying the order of ring formation by starting the synthetic sequence with the construction of the D-F ring. ${ }^{[51]}$ As shown in Scheme 11, coupling of dipeptide $\mathbf{2 1}$ with tryptophane amide 22 , prepared by palladium-catalyzed heteroannulation between $O$-iodoaniline and glutamic acid derivative, ${ }^{52]}$ afforded the tripeptide $\mathbf{2 3}$ in $80 \%$ yield. To our delight, the intramolecular Suzuki-Miyaura reaction of $\mathbf{2 3}$ under our previously developed conditions $\left[\mathrm{PdCl}_{2}(\mathrm{dppf}) \cdot \mathrm{CH}_{2} \mathrm{Cl}_{2}\right.$ (1.0 equiv), $\mathrm{K}_{2} \mathrm{CO}_{3}$ (10.0 equiv), dioxane/ $\mathrm{H}_{2} \mathrm{O}(\mathrm{v} / \mathrm{v}=15 / 1)^{3}$, $90{ }^{\circ} \mathrm{C}$ ] took place smoothly, in spite of the bulkiness of the TBS group, to afford the 16-membered cyclophane 24a, together with a small amount of partially $O$-desi- lylated compound $\mathbf{2 4 b}$, in $65 \%$ yield. The axial chirality of $\mathbf{2 4}$ was determined to be $a R$ by detailed NOE studies as well as characteristic high field shift of the $\alpha$ proton of amino acid $F(\delta=4.2 \mathrm{ppm})$. This assignment was ultimately confirmed by subsequent conversion of $\mathbf{2 4}$ to the natural product.

It is interesting to note that macrocycle $\mathbf{2 5}$ of complestatin type is readily isomerized to $\mathbf{2 6}$ of chloropeptin type under acidic conditions (Scheme 12). The planar chirality was preserved during the rearrangement. A possible mechanistic pathway accounting for this bond reorganization process is shown in the same scheme. ${ }^{[53]}$ Thus protonation of $\mathrm{C}_{6}$ (indole numbering) assisted by the lone-pair of nitrogen would afford the conjugated iminium salt, which upon nucleophilic attack of the neighboring phenol would provide the spirocyclopropane. Ring opening of cyclopropane would then provide the rearranged product with conservation of the axial chirality.

The completion of total synthesis of complestatin is highlighted in Scheme 13. [54] Cycloetherification of 27, obtained by a $[3+3]$ peptide segment coupling strat-

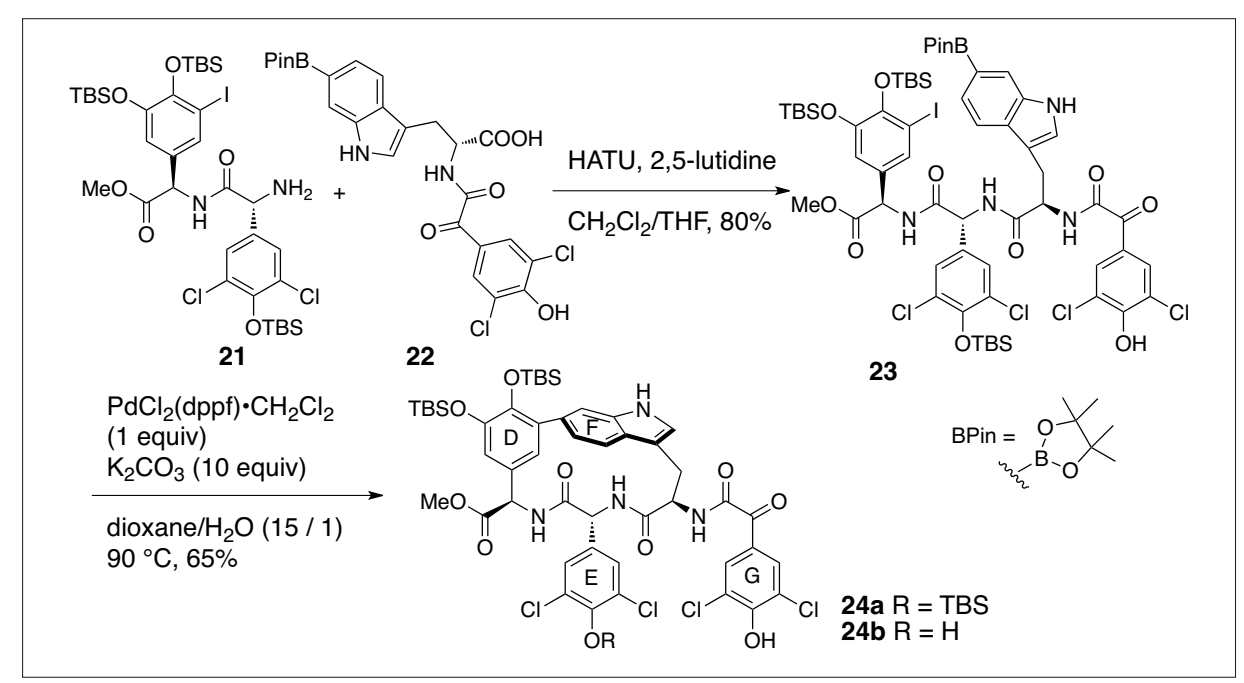

Scheme 11.

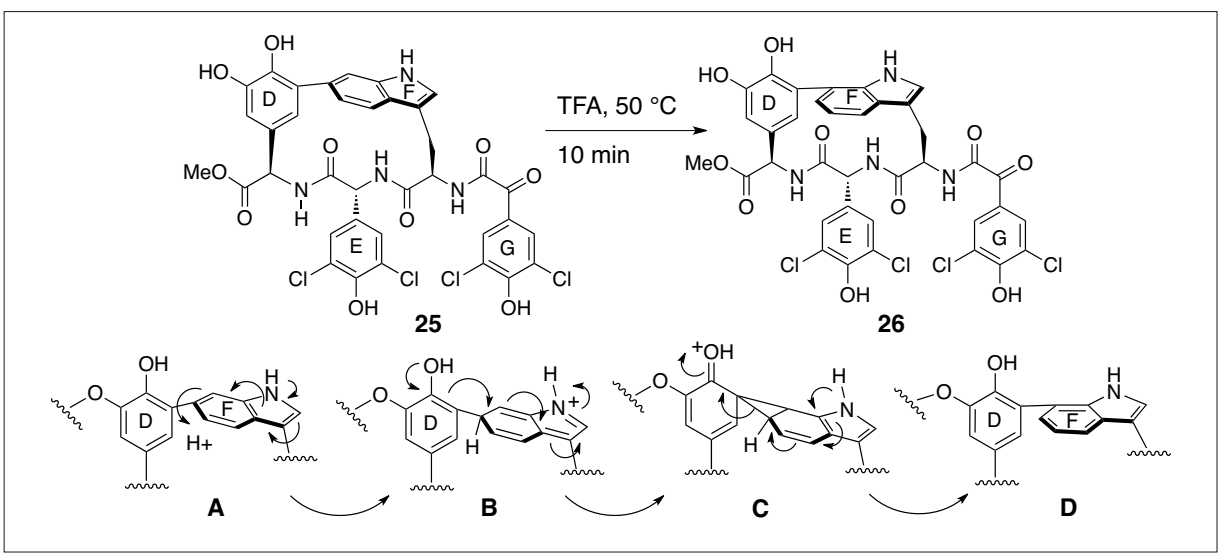

Scheme 12. egy, afforded bicycle $\mathbf{2 8}$ in $62 \%$ yield as a single atropisomer. The cyclization was regioselective since the alternative 14-membered, 17-membered and 20-membered cyclophanes resulting from the nucleophilic attack of the other hydroxy groups in rings $\mathrm{A}, \mathrm{C}, \mathrm{D}$ and $\mathrm{E}$ onto the fluoro nitro aromatic system were not observed. Detailed NMR studies indicated that the tertiary amide of residue $\mathrm{B}$ existed exclusively as a cis-conformer as was found in the natural product. We note herein that three chirality elements, namely: central chirality (six amino acid residues), axial chirality (D-F ring) and planar chirality (B-O-D ring), can be found in bicyclic compound 28. Reductive removal of nitro group via diazonium intermediate followed by $\mathrm{N}$ deprotection and saponification provided then the complestatin whose physical and spectroscopic data are found to be identical to those described for the natural product.

\section{Conclusion}

The major determinants in contemporary total synthesis have evolved and are 


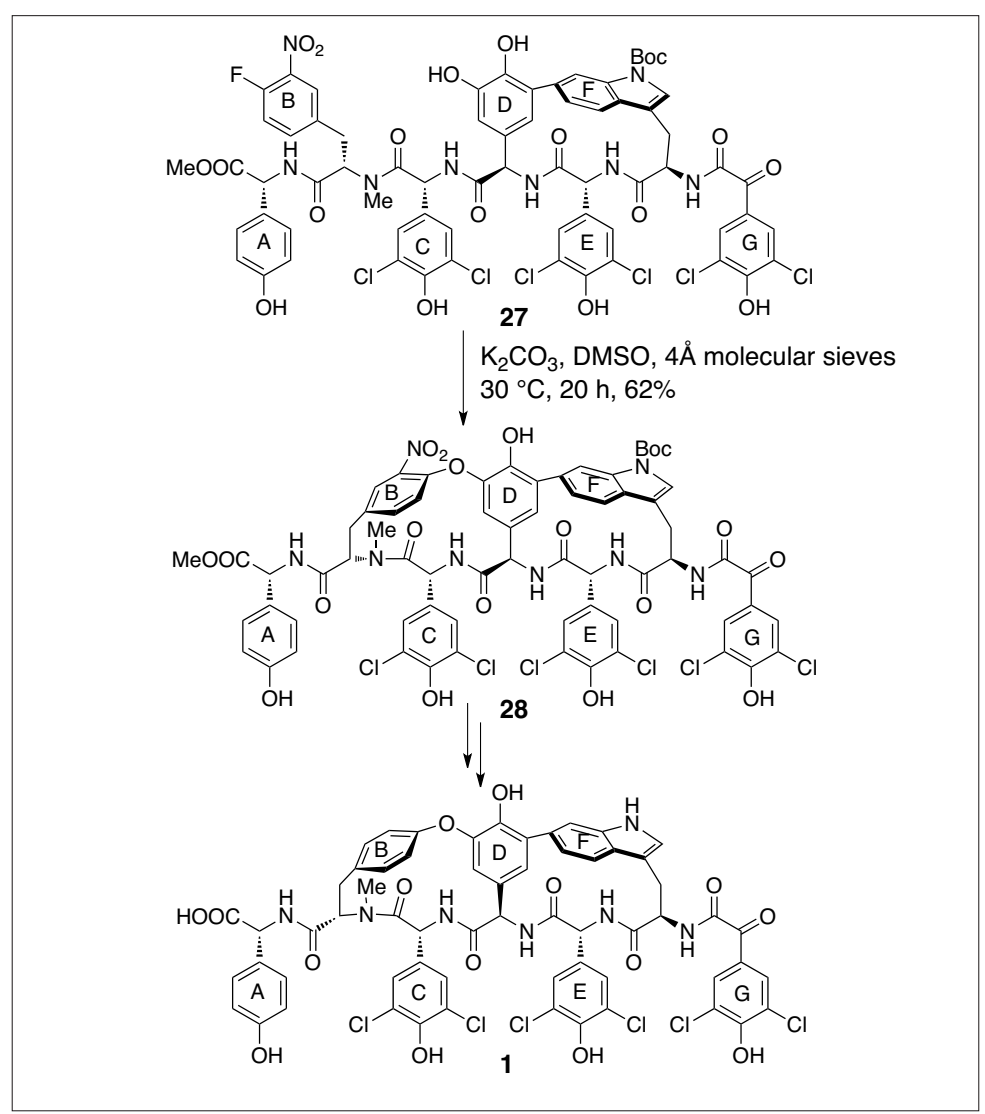

becoming more subtle and sophisticated. If one accepts the notion that virtually all structures can be synthesized in the laboratory given enough time and human resources, one might then pay particular attention to the selection of target, the planning of the synthetic strategy and the science that was discovered along the way. Fortunately enough, there is a creative synergism between target pursuits and methodology/strategy development. ${ }^{[55]}$ Total synthesis endeavors have helped to gain insights into chemical reactivity and selectivity principles and have served as the testing ground for the development of novel synthetic methodologies and strategies. Conversely, new strategy (methodology) developed during the pursuit of one specific target can find application in completely unrelated problems, enabling the synthesis of other previously inaccessible natural products. This is indeed the case of vancomycin synthesis. Although the efficiency of the total synthesis realized to date cannot match that of fermentation technology, the new synthetic strategies developed in the pursuit of this target have impacted the access to this type of macrocycles in general. Indeed, many otherwise elusive natural products, as well as designed molecules for specific biological properties, ${ }^{[56,57]}$ can now be synthesized thanks to those methodologies developed therefrom. As a matter of fact, the 16-membered C$\mathrm{O}-\mathrm{D}$ ring of macrocycles accessible only with difficulty some 25 years ago can now
Scheme 13.

be made in only two steps by combined use of Ugi-4CR ${ }^{[58]}$ and an intramolecular $\mathrm{S}_{\mathrm{N}} \mathrm{Ar}$ reaction. ${ }^{[59]}$ The synergy between total synthesis and synthetic strategy is therefore self-evident.

\section{Received: February 2, 2011}

[1] a) Y.-Z. Shu, J. Nat. Prod. 1998, 61, 1053; b) D. J. Newman, G. M. Cragg, K. M. Snader, Nat. Prod. Rep. 2000, 17, 215; c) L. Feliu, M. Planas, Int. J. Pep. Res. Therapeutics 2005, 11, 53; d) L. A. Wessjohann, E. Ruijter, D. GarciaRivera, W. Brandt, Mol. Diversity 2005, 9, 171.

[2] a) H. Kessler, Angew. Chem. 1982, 94, 509; Angew. Chem. Int. Ed. Engl. 1982, 21, 512; b) C. Toniolo, Int. J. Peptide Protein Res. 1990 35, 287; c) J. N. Lambert, J. P. Mitchell, K. D. Roberts, J. Chem. Soc., Perkin Trans. 12001 , 471; d) H. T. Hu, C. R. Xu, X. Song, T. J. Siahaan, J. Peptide Res. 2003, 61, 331.

[3] a) D. P. Fairlie, G. Abbenante, D. R. March, Curr. Med. Chem. 1995, 2, 654.

[4] M. A. Winnik, Acc. Chem. Res. 1985, 18, 73.

[5] a) J.-M. Lehn, 'Supramolecular Chemistry: Concepts and Perspectives', Wiley-VCH, Weinheim, 1995; b) F. M. Raymo, J. F. Stoddart, Chem. Rev. 1999, 99, 1643; c) M.-X. Wang, Chem. Commun. 2008, 4541.

[6] M. R. Ghadiri, J. R. Granja, R. A. Milligan, D. E. McRee, N. Khazanovich, Nature 1993, 366, 324.

[7] J. Zhu, Synlett 1997, 133.

[8] N. Miyaura, A. Suzuki, Chem. Rev. 1995, 95, 2457.

[9] A.-C. Carbonnelle, J. Zhu, Org. Lett. 2000, 2, 3477.

[10] a) D. H. Williams, Nat. Prod. Rep. 1996, 469; b) J. Zhu, Expert. Opin. Ther. Pat. 1999, 9, 1005; c) K. C. Nicolaou, C. N. C. Boddy, S. Bräse, N. Winssinger, Angew. Chem. Int. Ed. 1999, 38,
2096; d) R. D. Süssmuth, ChemBioChem. 2002 , 3, 295; e) D. Kahne, C. Leimkuhler, W. Lu, C. T. Walsh, Chem. Rev. 2005, 105, 425.

[11] a) D. H. Williams, A. J. Maguire, W. Tsuzuki, M. S. Westwell, Science 1998, 280, 711; b) M. Ge, Z. Chen, H. R. Onishi, J. Kohler, L. L. Silver, R. Kerns, S. Fukuzawa, C. Thompson, D. Kahne, Science 1999, 284, 507; c) U. S. Eggert, N. Ruiz, B. V. Falcone, A. A. Branstrom, R. C. Goldman, T. J. Silhavy, D. Kahne, Science 2001, 294, 361.

[12] R. F. Service, Science 1999, 285, 184.

[13] a) M. J. Stone, M. S. Van Dyk, P. M. Booth, D. H. Williams, J. Chem. Soc., Perkin Trans I 1991, 1629; b) A. J. Pearson, J. G. Park, J. Org. Chem. 1992, 57, 1744.

[14] S. Yamamura, S. Nishiyama, J. Synth. Org Chem. Jpn. 1997, 55, 1029

[15] S. Nishiyama, Y. Suziki, S. Yamamura, Tetrahedron Lett. 1986, 27, 559.

[16] S. Nishiyama, K. Nakamura, Y. Suzuki, S. Yamamura, Tetrahedron Lett. 1986, 27, 4481.

[17] T. Inoue, T. Inaba, I. Umezawa, M. Yuasa, H Itokawa, K. Ogura, K. Komatsu, H. Hara, O. Hoshino, Chem. Pharm. Bull. 1995, 43, 1325.

[18] Y. Suzuki, S. Nishiyama, S. Yamamura, Tetrahedron Lett. 1989, 30, 6043.

[19] D. A. Evans, J. A. Elleman, K. M. Devries, J. Am. Chem. Soc. 1989, 111, 8912.

[20] D. A. Evans, J. C. Barrow, P. S. Watson, A M. Ratz, C. J. Dinsmore, D. A. Evrard, K. M. DeVries, J. A. Ellman, S. D. Rychnovsky, J. Macour, J. Am. Chem. Soc. 1997, 119, 3419.

[21] D. L. Boger, J. Zhou, J. Am. Chem. Soc. 1993, $115,11426$.

[22] D. L. Boger, M. A. Patane, J. Zhou, J. Am Chem. Soc. 1994, 116, 8544.

[23] D. L. Boger, Y. Nomoto, B. R. Teegarden, J. Org. Chem. 1993, 58, 1425.

[24] a) R. Beugelmans, G. P. Singh, M. Bois-Choussy, J. Chastanet, J. Zhu, J. Org. Chem. 1994, 59, 5535 ; b) J. Zhu, J. P. Bouillon, G. P. Singh, J. Chastanet, R. Beugelmans, Tetrahedron Lett. 1995, 36, 7081; c) J. Zhu, R. Beugelmans, S. Bourdet, J. Chastanet, G. Roussi, J. Org. Chem. 1995, 60, 6389; d) R. Beugelmans, S. Bourdet, J. Zhu, Tetrahedron Lett. 1995, 36, 1279; e) M. Bois-Choussy, R. Beugelmans, J. P. Bouillon, J. Zhu, Tetrahedron Lett. 1995, 36, 4781; f) R. Beugelmans, A. Bigot, M. Bois-Choussy, J. Zhu, J. Org. Chem. 1996, 61, 771; g) M. BoisChoussy, L. Neuville, R. Beugelmans, J. Zhu, J. Org. Chem. 1996, 61, 9309.

[25] For a review on conformation-directed macrocyclization, see: J. Blankenstein, J. Zhu, Eur. J. Org. Chem. 2005, 1949.

[26] R. Beugelmans, A. Bigot, J. Zhu, Tetrahedron Lett. 1994, 35, 7391.

[27] A. Bigot, M. E. Tran Huu Dau, J. Zhu, J. Org. Chem. 1999, 64, 6283.

[28] G. Islas-Gonzalez, J. Zhu, J. Org. Chem. 1999, $64,914$.

[29] a) J. Zhu, T. Laïb, J. Chastanet, R. Beugelmans, Angew. Chem. 1996, 108, 2664; Angew. Chem. Int. Ed. 1996, 35, 2517; b) T. Temal-Laïb, J. Chastanet, J. Zhu, J. Am. Chem. Soc. 2002, 124, 583.

[30] P. Cristau, T. Temal-Laïb, M. Bois-Choussy, M. T. Martin, J. P. Vors, J. Zhu, Chem. Eur. J. 2005 11, 2668.

[31] R. Beugelmans, M. Bois-Choussy, C. Vergne, J. P. Buillon, J. Zhu, J. Chem. Soc., Chem. Commun. 1996, 1029.

[32] a) D. A. Evans, M. R. Wood, B. W. Trotter, T. I. Richardson, J. C. Barrow, J. L. Katz, Angew. Chem. 1998, 110, 2864; Angew. Chem. Int Ed. 1998, 37, 2700; b) K. C. Nicolaou, M. Takayanagi, N. F. Jain, S. Natarajan, A. E. Koumbis, T. Bando, J. M. Ramanjulu, Angew. Chem. 1998, 110, 2881; Angew. Chem. Int. Ed. 1998, 37, 2717; c) D. L. Boger, S. Miyazaki, S. H. Kim, J. H. Wu, O. Loiseleur, S. L. Castle, J. 
Am. Chem. Soc. 1999, 121, 3226.

[33] a) U. Schmidt, V. Leitenberger, H. Griesser, J. Schmidt, R. Meyer, Synthesis 1992, 1248; b) S. Boisnard, A.-C. Carbonnelle, J. Zhu, Org. Lett. 2001, 3, 2061; c) H. Waldmann, Y.-P. He, H. Tan, L. Arve, H.-D. Arndt, Chem. Commun. 2008, 5562.

[34] a) M. F. Semmelhack, L. S. Ryono, J. Am. Chem. Soc. 1975, 97, 3873

[35] D. H. R. Barton, R. D. Bracho, C. J. Potter, D. A. Widdowson, J. Chem. Soc., Perkin Trans. 1 1974, 2278; b) D. A. Evans, C. J. Dinsmore, A. M. Ratz, D. A. Evrard, J. C. Barrow, J. Am. Chem. Soc. 1997, 119, 3417.

[36] K. Ito, H. Tanaka, Chem. Pharm. Bull. 1974, 22, 2108.

[37] R. Lepine, J. Zhu, Org. Lett. 2005, 7, 2981.

[38] J. Dufour, L. Neuville, J. Zhu, Synlett 2008, 2355.

[39] J. Dufour, L. Neuville, J. Zhu, Chem. Eur. J. 2010, 16, 10523

[40] M. Bois-Choussy, P. Cristau, J. Zhu, Angew. Chem. 2003, 115, 4370; Angew. Chem. Int. Ed. 2003, 42, 4238 .

[41] I. Kaneko, D. T. Fearon, K. F. Austen, J. Immunol. 1980, 124, 1194.

[42] a) H. Seto, T. Fujioka, K. Furihata, I. Kaneko, S. Takahashi, Tetrahedron Lett. 1989, 30, 4987; b) I. Kaneko, K. Kamoshida, S. Takahashi, J. Antibiot. 1989, 42, 236

[43] a) H. Gouda, K. Matsuzaki, H. Tanaka, S. Hirono, S. Omura, J. A. McCauley, P. A Sprengeler, G. T. Furst, A. B. Smith III, J. Am. Chem. Soc. 1996, 118, 13087; b) S. B. Singh, H. Jayasuriya, G. M. Salituro, D. L. Zink, A. Shafiee, B. Heimbuch, K. C. Silverman, R. B. Lingham, O. Genilloud, A. Teran, D. Vilella, P. Felock, D. Hazuda, J. Nat. Prod. 2001, 64, 874.

[44] a) H. Tanaka, K. Matsuzaki, H. Nakashima, T. Ogino, A. Matsumoto, H. Ikeda, H. B. Woodruff, S. Omura, J. Antibiot. 1997, 50, 58; b) K. Matsuzaki, T. Ogino, T. Sunazuka, H. Tanaka, S. Omura, J. Antibiot. 1997, 50, 66.

[45] S. Y. Soo, B.-S. Yun, I.-J. Ryoo, J.-S. Choi, C.-K. Joo, S.-Y. Chang, J.-M. Chung, S. Oh, B. J. Gwag, I. D. Yoo, J. Pharmacology and Experimental Therap. 2001, 299, 377.
[46] H. Deng, J.-K. Jung, T. Liu, K. W. Kuntz, M. L. Snapper, A. H. Hoveyda, J. Am. Chem. Soc. 2003, 125, 9032.

[47] T. Shinohara, H. Deng, M. L. Snapper, A. H. Hoveyda, J. Am. Chem. Soc. 2005, 127, 7334.

[48] J. Garfunkle, F. S. Kimball, J. D. Trzupek, S. Takizawa, H. Shimamura, M. Tomishima, D. L. Boger, J. Am. Chem. Soc. 2009, 131, 16036.

[49] F. Dettner, A. Hänchen, D. Schols, L. Toti, A Nuber, R. D. Süssmuth, Angew. Chem. 2009, 121, 1888; Angew. Chem. Int. Ed. 2009, 48, 1856.

[50] Y. Jia, M. Bois-Choussy, J. Zhu, Angew. Chem. 2008, 120, 4235; Angew. Chem. Int. Ed. 2008, 47, 4167.

[51] Y. Jia, M. Bois-Choussy, J. Zhu, Org. Lett. 2007, 9, 2401.

[52] Y. Jia, J. Zhu, J. Org. Chem. 2006, 71, 7826.

[53] a) V. R. Hegde, P. Dai, M. Patel, V. P. Gullo, Tetrahedron Lett. 1998, 39, 5683; b) H. Jayasuriya, G. M. Salituro, S. K. Smith, J. V. Heck, S. J. Gould, S. B. Singh, C. F. Homnick, M. K. Holloway, S. M. Pitzenberger, M. A. Patane, Tetrahedron Lett. 1998, 39, 2247.

[54] Z. H. Wang, M. Bois-Choussy, Y. Jia, J. Zhu, Angew. Chem. 2010, 122, 2062; Angew. Chem. Int. Ed. 2010, 49, 2018.

[55] Recent example of synthesis of biaryl-containing macrocycles featuring a Z-selective RCM, see: L. Chausset-Boissarie, R. Avrai, G. R. Cumming, C. Besnard, E. P. Kundig, Chem. Commun. 2010, 46, 6264.

[56] a) Y. Jia, N. Ma, Z. Liu, M. Bois-Choussy, E. Gonzalez-Zamora, A. Malabarba, C. Brunati, J. Zhu, Chem. Eur. J. 2006, 12, 5334.

[57] B. M. Crowley, D. L. Boger, J. Am. Chem. Soc. 2006, 128, 2885.

[58] a) A. Dömling, I. Ugi, Angew. Chem. 2000, 112, 3300; Angew. Chem. Int. Ed. 2000, 39, 3168; b) J. Zhu, Eur. J. Org. Chem. 2003, 1133; b) A. Dömling, Chem. Rev. 2006, 106, 17.

[59] a) P. Cristau, J. P. Vors, J. Zhu, Org. Lett. 2001, 3, 4079; b) P. Cristau, J. P. Vors, J. Zhu, Tetrahedron 2003, 59, 7859; c) P. Cristau, J. P. Vors, J. Zhu, Tetrahedron Lett. 2003, 44, 5575. 